\title{
LR1, a lipopolysaccharide-responsive factor with binding sites in the immunoglubulin switch regions and heavy-chain enhancer
}

\author{
Marna Williams and Nancy Maizels ${ }^{1}$ \\ Department of Molecular Biophysics and Biochemistry, Yale Medical School, New Haven Connecticut 06510 USA
}

In nuclear extracts of primary murine B lymphocytes cultured with LPS we have identified an inducible DNA-binding activity that is a candidate regulator of isotype-switch recombination. This LPS-responsive factor, which we refer to as LR1, is induced in LPS-cultured primary cells with kinetics that parallel isotype-switch recombination. LR1 binds sequences from the $S \gamma 1, S \gamma 3$, and $S \alpha$ switch regions, as well as the heavy-chain enhancer, and these binding sites define a consensus that occurs in each of the murine switch regions. LR1 activity is present in pre-B and B-cell lines but absent from primary $B$ cells that have not been cultured with mitogen and from highly differentiated B-cell lines. LR1-binding activity depends on phosphorylation and is lost following incubation of nuclear extracts with acid phosphatase. The LPS inducibility and phosphorylation dependence of LR1 activity suggest that this factor monitors kinase-dependent events in cell development and communicates them to the chromosome. The locations of its binding sites and the kinetics of its induction are consistent with a role for LR1 in regulation of isotype switching.

[Key Words: B cells; heavy-chain enhancer; immunoglobulins; protein kinase; switch regions]

Received June 11, 1991; revised version accepted September 26, 1991.

Isotype switching is a regulated recombination event that joins an expressed VDJ region to a new downstream constant region, deleting the DNA between (for review, see Blackwell and Alt 1989; Esser and Radbruch 1990). Switch recombination represents a key defense against foreign substances, as each constant region is adapted to remove antigen in particular ways. Switching occurs only after a B cell has been stimulated by antigen, and the recombination process involves domains of sequence called switch or S regions, which are located in the intron upstream of each constant region. Each switch region consists of many reiterations of its own characteristic G-rich sequence motif, punctuated by unique or less highly repetitive sequences (Davis et al. 1980; Dunnick et al. 1980; Kataoka et al. 1980, 1981; Sakano et al. 1980; Nikaido et al. 1981, 1982; Szurek et al. 1985; Mowatt and Dunnick 1986).

In primary cell culture, the mitogen bacterial lipopolysaccharide (LPS) stimulates resting B cells to divide, produce antibodies, and undergo isotype switching. Culture with LPS alone induces efficient switching to $\gamma 3$ (Radbruch and Sablitzky 1983), and inclusion of particular lymphokines or cytokines in LPS-cultured cells targets

\footnotetext{
${ }^{1}$ Corresponding author.
}

switching to other isotypes. For example, LPS in combination with interleukin-4 (IL-4) promotes switching mainly to $\gamma 1$ (Isakson et al. 1982; Bergstedt-Lindquist et al. 1984; Vitetta et al. 1985; Noma et al. 1986; Paul and Ohara 1987) and also to $\epsilon$ (Coffman and Carty 1986; Coffman et al. 1986; Snapper et al. 1988), LPS combined with gamma interferon (IFN- $\gamma$ ) enhances $\gamma 2$ a switching (Snapper and Paul 1987; Finkelman et al. 1988), and LPS combined with transformation grow th factor- $\beta$ (TGF- $\beta$ ) stimulates switching to $\alpha$ (Coffman et al. 1989). In these primary cell cultures, LPS provides a signal for cell activation that substitutes for the antigen-dependent stimulation of cell- surface immunoglobulin molecules that occurs in vivo. Unlike antigen-dependent activation, LPS does not stimulate phosphotidyl inositol breakdown or calcium flux but may instead function by directly activating protein kinase $\mathrm{C}$ (Bijsterboch et al. 1985; Guy et al. 1985).

How does the extracellular signal delivered by LPS and lymphokines activate the recombination apparatus? The inducibility of switching in cultured primary cells argues that specific and regulated protein-DNA interactions must be prerequisite to switch recombination. We have identified a factor in nuclear extracts of LPS-stimulated primary murine B cells that is a candidate regulator of switch recombination. This LPS-responsive DNA-bind- 
ing activity, which we refer to as LR1, binds specifically to sequences in the $S \gamma 1, S \gamma 3$, and $S \alpha$ switch regions and in the heavy-chain enhancer $(\mathrm{E} \mu)$, and these binding sites define a consensus sequence that occurs as a nonrepetitive element in each of the murine switch regions. LR1 activity is not present in resting B cells but is induced when primary cells are cultured with LPS or LPS + IL4, and the relatively slow induction of LR1 activity parallels the induction of switch recombination. LR l activity is present in pre-B and B-cell lines, although not in plasmacytomas or hybridomas, which represent later stages of cell development. The DNA-binding activity of LRl is sensitive to dephosphorylation of the nuclear extract, suggesting that this factor responds to protein kinasemediated events in cell regulation.

\section{Results}

\section{An inducible factor binds a sequence in $S \gamma 1$}

Like other $S \gamma$ regions, $S \gamma l$ is comprised of numerous repeats of a G-rich 49-mer sequence, but in $S \gamma 1$ the 49-mer repeats are bounded and interrupted by two pairs of long direct repeats, DRI and DRII, as shown in Figure 1 (Mowatt and Dunnick 1986). As the G-rich repeats within the switch regions have a plausible role as structural elements facilitating DNA-DNA interaction (Sen and Gilbert 1988), we reasoned that regulatory factors that monitor LPS-dependent cell activation or target switching to $\gamma 1$ might bind within the conserved DRI-DRII regions in Syl. We generated nuclear extracts from primary murine spleen cells cultured with LPS + IL4 and tested for binding activity by gel mobility-shift assay. Figure 2 shows that the 152-bp BamHI-PstI fragment from the region between DRI and DRII is active in binding and that further digestion of this fragment with DdeI produces a 92-bp DdeI-PstI fragment that is also active. Two downstream fragments, a 102-bp PstI-PstI fragment and a 150-bp PstI-BamHI fragment, showed no binding activity using any of a variety of reaction conditions in which ionic strength, divalent cation concentration, poly[d(IC)] competitor concentration, and binding temperature were systematically varied (Fig. 2 and data not shown). No retarded band was evident when fragments were incubated in the absence of nuclear extract prior to

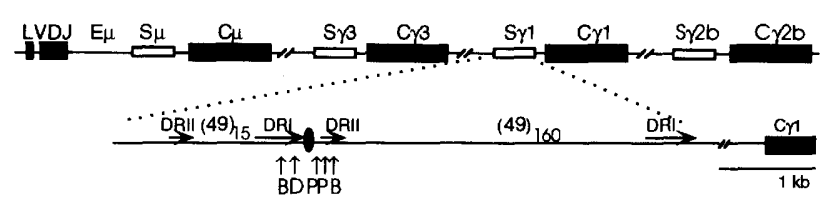

Figure 1. The $S \gamma 1$ region within the murine immunoglobulin heavy-chain locus. Top Diagram of part of the murine immunogloblin heavy-chain locus, showing a rearranged variable region (LVDI) and downstream constant regions (solid boxes), and switch regions (open boxes). (Bottom) Syl switch region, show. ing direct repeats DRI and DRII and sites for BamHI (B), PstI (P), and $D \operatorname{deI}(\mathrm{D})$ that defined fragments tested in gel shifts shown in Fig. 2.

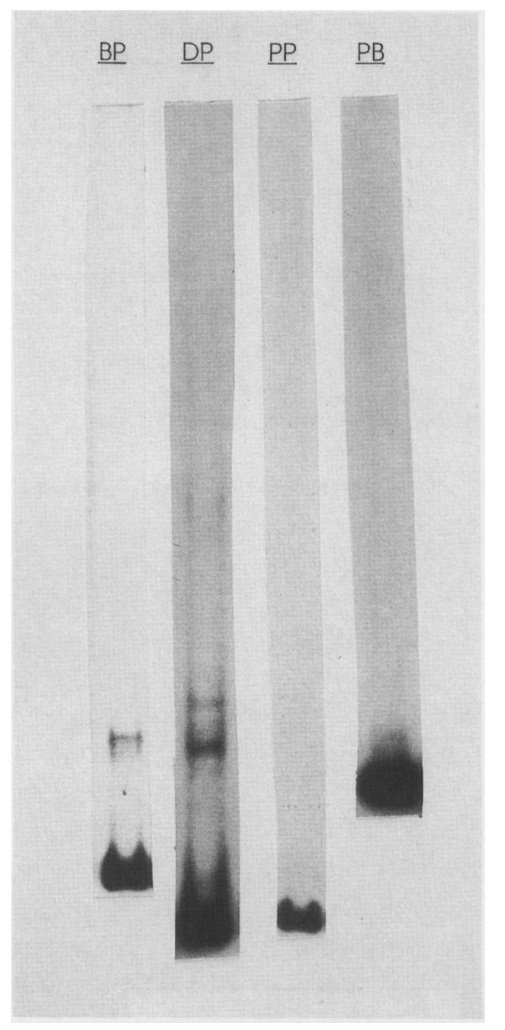

Figure 2. Gel mobility-shift assays of fragments from $S \gamma 1 .{ }^{32} \mathrm{P}-$ Labeled restriction fragments were incubated with nuclear extract from primary murine spleen cells cultured for 5 days with LPS + IL4, and protein-DNA complexes were resolved on a $5 \%$ polyacrylamide gel. Fragments assayed: (BP) A 152-bp BamHIPstI fragment containing DRl and DRII sequences; (DP) a 92-bp DdeI-Pst fragment derived from $\mathrm{BP}$ by $D d e I$ digestion; $(\mathrm{PP})$ a 102-bp PstI-PstI fragment containing DRII sequences; (PB) a 150-bp PstI-BamHI fragment containing DRII sequences.

electrophoresis, and competition experiments verified the sequence specificity of the observed shift (data not shown).

\section{Localization of the binding site}

Methylation interference (Siebenlist and Gilbert 1980) localized the binding region to a 17 -bp sequence that contains two nearly perfect inverted repeats separated by a short (7-bp) spacer (Fig. 3). While methylation of most purines in the binding region inhibited interaction with the binding activity, methylation at G14 enhanced binding [this position is marked by an asterisk ( $\left.{ }^{\star}\right)$ in Fig. 3]. By mutagenesis we generated a transition from $G$ to $A$ at this position, and by gel-shift analysis we showed that this single-base change decreases binding significantly (Fig. 4A). Competition experiments with synthetic oligonucleotides carrying the wild-type or Gl4A mutant sequences (shown in Fig. 4B), show that the DNA-binding activity has 10 - to 15 -fold greater affinity for the wild type than for the mutant sequence, attesting to the specificity of the binding interaction. 


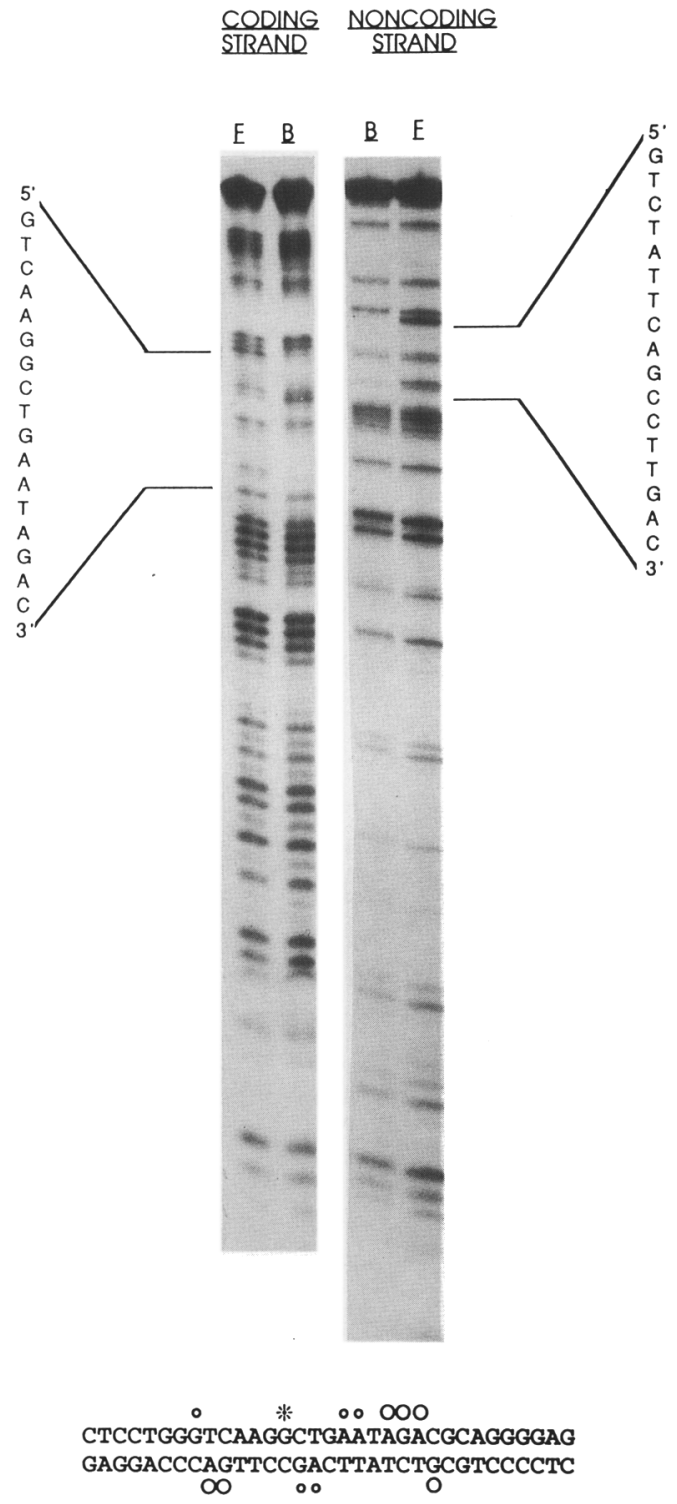

Figure 3. Methylation interference analysis. The 3 '-end-labeled coding strand (from DP; Fig. 1) and noncoding strand (from BP) were partially methylated prior to binding with nuclear extract from primary murine spleen cells cultured with LPS + IL4. Free (F) and bound (B) fragments were resolved on a native gel, subjected to chemical cleavage, and cleavage products were analyzed on a $10 \%$ polyacrylamide- $8 \mathrm{M}$ urea sequencing gel. The binding region is shown below the autoradiograph, with methylation-sensitive positions marked. $(\mathrm{O})$ strong interference; $(0)$ partial interference; $\left.\left.\right|^{*}\right)$ methylation enhances binding.

\section{LR1 activity is LPS inducible and restricted to a limited period of $B$-cell development}

Figure $5 \mathrm{~A}$ shows that primary $\mathrm{B}$ cells that have not been cultured with mitogen lack the binding activity but that culture with either LPS or LPS + IL4 induces a binding activity that produces shifted bands of identical mobility. To establish that the same activity is induced by culture with LPS or LPS + IL4, the synthetic duplex carrying the G14A point mutation was used to assay binding; factors present in these extracts do not bind the mutant sequence. We refer to the LPS-responsive DNAbinding activity that is sensitive to the G14A mutation as LR1.

The effects of LPS are pleiotropic, and different aspects of the LPS response display distinctive kinetics. For example, c-myc expression increases 15-fold within $2 \mathrm{hr}$ of LPS stimulation (Keath et al. 1984), whereas $\mathrm{C} \mu$ transcripts and IgM antibody-secreting cells begin to increase dramatically after $24 \mathrm{hr}$ in culture. Isotype switching and increased production of $\mathrm{C} \gamma$ transcripts peak from about day 3 to 5 (Howard and Paul 1983; Esser and Radbruch 1989). As shown in Figure 5B, LR1 activity is not induced after $2 \mathrm{hr}$ of culture with LPS but is fully induced by 24 $\mathrm{hr}$. In other experiments the kinetics of induction of LR1 activity display a prolonged and broad activity peak between day 1 and 5, and these kinetics correlate with the appearance of IgG-positive cells in culture (data not shown).

Assays of LR1 activity in nuclear extracts of a variety of cell lines representing different stages of B-cell development showed that LR1 activity is present in two pre-B

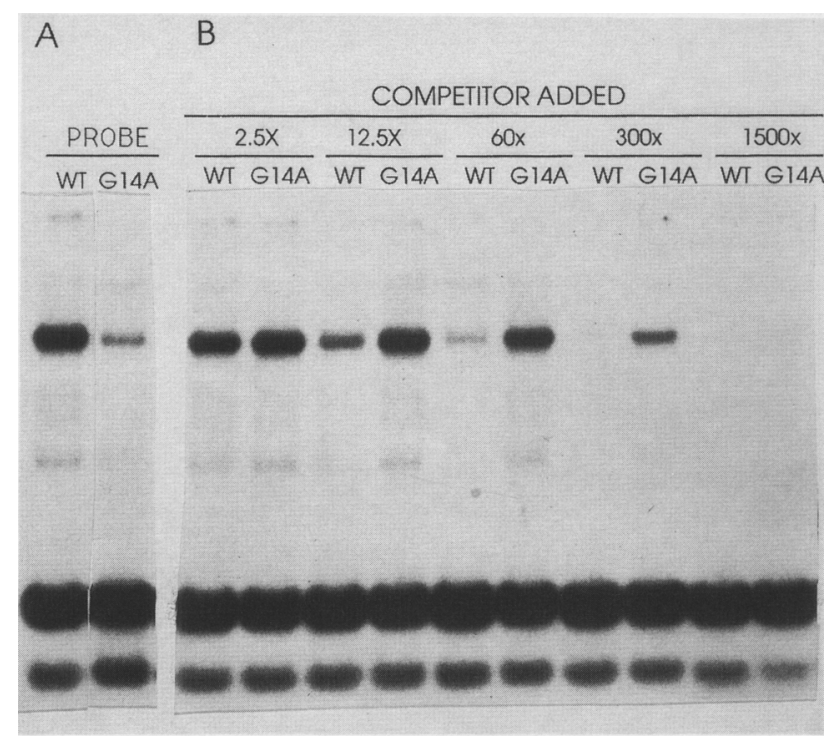

Figure 4. Binding to the $S \gamma l$ site in the presence of wild-type and G14A mutant competitor. $(A)^{32} \mathrm{P}$-Labeled synthetic duplex probe containing the wild-type (WT) or mutant (G14A) S $\gamma 1$ binding sequence was incubated with nuclear extract from primary spleen cells cultured with LPS + IL4. $(B)^{32} \mathrm{P}$-Labeled synthetic duplex probe containing the wild-type $S \gamma 1$-binding sequence was incubated with nuclear extract from primary spleen cells cultured with LPS + IL4; competitor unlabeled synthetic duplexes, carrying the wild-type or mutant G14A S $\gamma 1$ sequence, were added to the assays prior to the addition of nuclear extract in amounts varying from $2.5-$ to 1500 -fold molar excess. Protein-DNA complexes were resolved on a $5 \%$ polyacrylamide gel. 

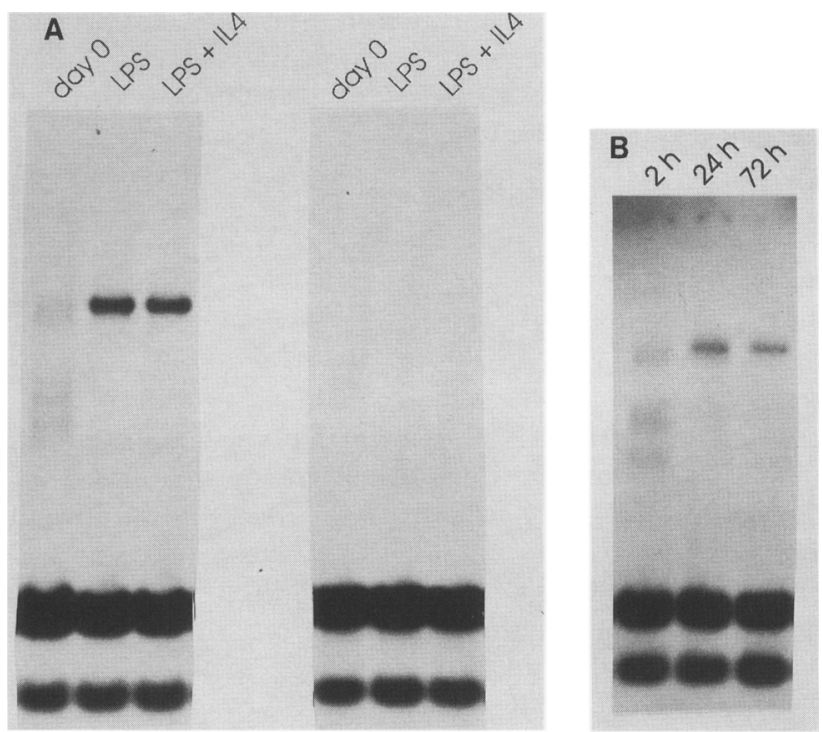

Figure 5. LRl induction in primary B cells. ${ }^{32} \mathrm{P}$-Labeled synthetic duplex probe containing the wild-type or mutant G14A Syl-binding sequence was incubated with nuclear extract, and protein-DNA complexes were resolved on a $5 \%$ polyacrylamide gel. (A) (Left) Wild-type site; (right) mutant G14A site. Nuclear extracts were from spleen cells that had not been cultured in vitro (day 0 ) and spleen cells that had been cultured for 5 days with LPS or with LPS + IL4 prior to extract preparation. (B) Nuclear extracts were from spleen cells cultured with $20 \mu \mathrm{g} / \mathrm{ml}$ LPS for 2, 24, and $72 \mathrm{hr}$. cell lines, PD31 and 70Z/3, as well as in the murine B-cell line WEHI 279.1 and in the human Epstein-Barr virus (EBV)-transformed Burkitt's lymphoma line, Raji (Fig. 6). (Note that there are two binding activities in Raji cells, but only the lower band, which is sensitive to the G14A mutation, corresponds to LR1.) LR1 activity is not evident at later stages of B-cell development nor does it correlate with production of IgG1 or IgG3 antibodies as it is absent from nuclear extracts of ANO2 and 8-11A, hybridomas that produce IgG1 and IgG3 antibodies, respectively. (Note that the shifted band comigrating with LR1 is not sensitive to the G14A mutation). LR1 activity is also not evident in primary murine liver cells; in $\mathrm{J} 558 \mathrm{~L}$, a murine plasmacytoma line; in S49, a murine T-cell line; in $\mathrm{A} 92 \mathrm{~L}$, a murine fibroblast line (a shifted band is apparent in this lane, but it neither comigrates with LR1 nor exhibits sensitivity to G14A); or in HeLa, a human epithelial cell line.

\section{$L R 1$ binds in the $S \gamma 1, S \alpha$, and $S \gamma 3$ switch regions,} and in the heavy-chain enhancer

The observation that culture either with LPS or with LPS + IL4 can induce LR1 activity suggests that the function of LR1 is to monitor LPS-induced cell activation rather than to target switch recombination to a particular isotype, making it likely that LRI might bind to sites in other switch regions as well. A computer search

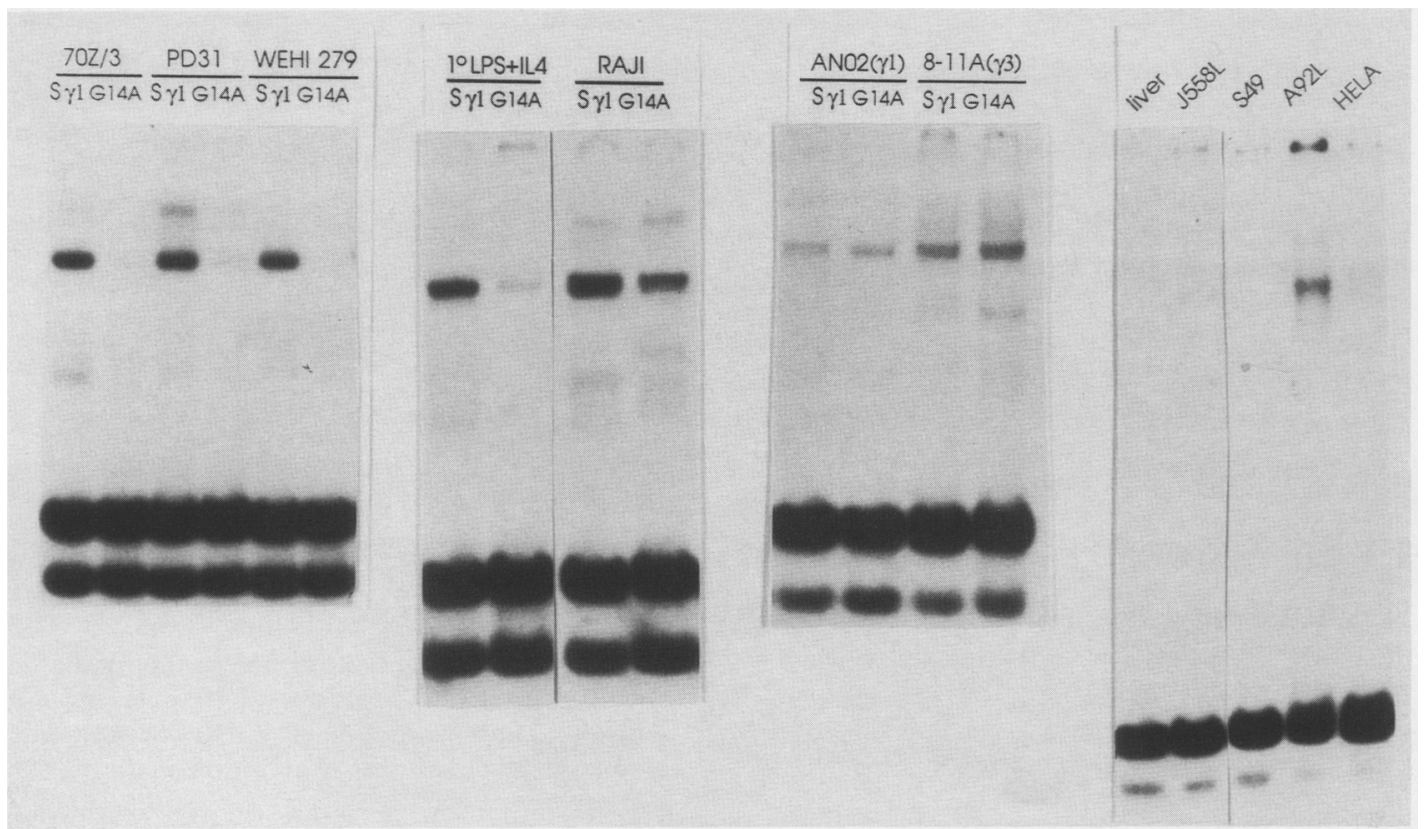

Figure 6. Cell type specificity of LR1 activity. ${ }^{32} \mathrm{P}$-Labeled synthetic duplex probe containing the wild-type Syl-binding sequence was incubated with nuclear extracts from murine pre-B-cell lines 70Z/3 and PD31; murine B-cell line WEHI 279.1; primary murine spleen cells that had been cultured with LPS + IL4 for 5 days; Raji, a human Burkitt's lymphoma line; hybridoma ANO2, which secretes IgG1 antibodies; hybridoma 8-11A, which secretes IgG3 antibodies; primary murine liver cells; J558L, a murine plasmacytoma line; S49, a murine T-cell line; A92L, a murine fibroblast line; and HeLa, a human epithelial cell line. Each assay contained $5 \mu \mathrm{g}$ of total protein, except for the Raji extract assays, which contained only $1 \mu \mathrm{g}$ protein. Extracts inactive for LRl binding were tested for total protein activity by binding to the U2 Oct-1 site (Ares et al. 1987). 
for matches to the binding region revealed at least one similar sequence in each of the murine switch regions, as well as one in the heavy-chain enhancer. We generated synthetic oligonucleotide duplexes to match one site in $\mathrm{S} \alpha$, one site in $\mathrm{S} \gamma 3$, and the site in $\mathrm{E} \mu$. Figure 7 shows that an inducible activity in LPS-cultured cells binds to each of these sequences and that the shifted bands are of identical mobility to LRl bound to the S $\gamma 1$ sequence; the same activity is also present in PD31 cells. To verify that the binding activity is LR1, we have also tested binding and competition using factor that has been partially purified by affinity chromatography and showed that the $S \gamma 1, S \gamma 3, S \alpha$, and $E \mu$ sequences compete for the same factor (M. Williams and N. Maizels, in prep.). These four binding sequences define a consensus binding site, shown below. From one to several copies of this site are evident in each of the murine $S$ regions.

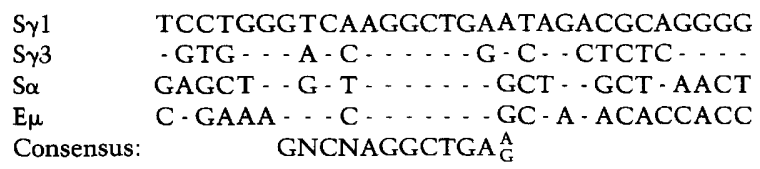

\section{Phosphorylation regulates LR1 activity}

Phosphorylation can stimulate or inhibit the activity of proteins that bind DNA (Mohr et al. 1987; Hoeffler et al. 1988; Prywes et al. 1988; Raychaudhuri et al. 1989; Ghosh and Baltimore 1990; Jackson et al. 1990; Tanaka and Herr 1990), and the polyclonal stimulation induced by LPS proceeds through kinase-dependent signaling pathways (Bijsterbosch et al. 1985, 1986; Guy et al. 1985). To determine whether LR1 activity depends on phosphorylation, nuclear extracts from Raji cells or primary B cells cultured with LPS or LPS + IL4 were treated briefly with acid phosphatase and then assayed for binding. Figure 8 shows that LR1-binding activity in each of these extracts is sensitive to treatment with phosphatase. Phosphatase treatment of the Raji cell ex-

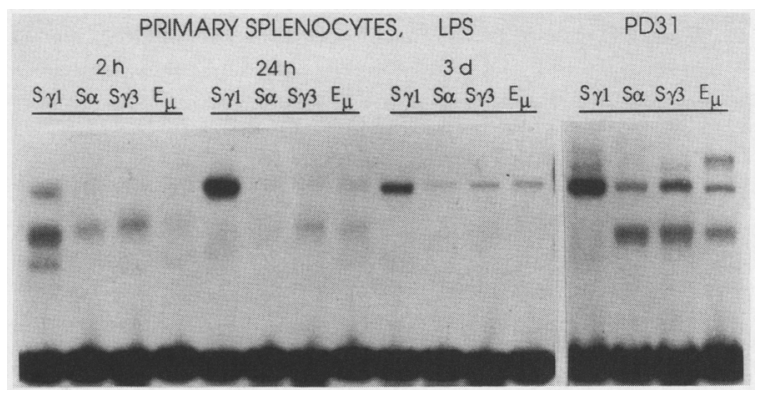

Figure 7. Sequences from other switch regions and the heavychain enhancer are binding sites for LR1. Gel mobility shifts of fragments carrying sequences from $S \alpha, S \gamma 3$, and $E \mu$ that match the LR1 site in $S \gamma 1 .{ }^{32} \mathrm{P}$-Labeled synthetic duplex probes carrying $S \gamma 1, S \alpha, S \gamma 3$, or $E \mu$ sequences were incubated with nuclear extract from primary murine spleen cells cultured with LPS for $2 \mathrm{hr}, 24 \mathrm{hr}$, or 3 days, or from PD31 pre-B cells. Protein-DNA complexes were resolved on a $5 \%$ acrylamide gel.

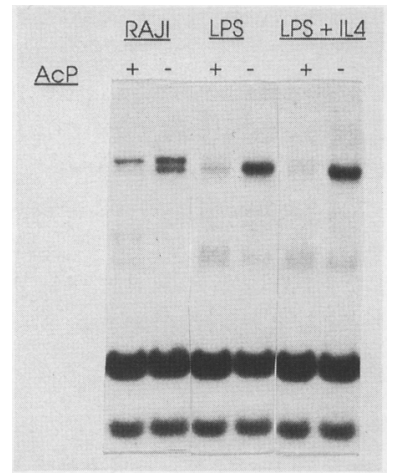

Figure 8. Acid phosphatase sensitivity of LR1 binding. ${ }^{32} \mathrm{P}$ Labeled synthetic duplex probe carrying the Syl-binding sequence was incubated with nuclear extracts, and protein-DNA complexes were resolved on a $5 \%$ polyacrylamide gel. Extracts were from Raji cells and primary murine spleen cells cultured for 5 days with LPS or with LPS + IL4. $1+\mid$ Assays with extracts that had been pretreated with acid phosphatase for $10 \mathrm{~min}$ at room temperature prior to addition of probe; $|-|$ no acid phosphatase treatment.

tract is particularly informative, because dephosphorylation diminishes binding of the lower but not the upper band in the doublet. It is the lower band in the Raji cell extracts that shows the same sensitivity to the G14A mutation as the binding activity induced by LPS in murine B cells, and the similar phosphatase sensitivity suggests further that LR1 activity is conserved in human and murine B cells. Control experiments showed that preincubation in buffer alone did not diminish binding and that inclusion of inhibitors of acid phosphatase 12 $\mathrm{mm}$ molybdate or $60 \mathrm{~mm}$ sodium phosphate) partially preserved binding activity (data not shown). Although these experiments show that LR1 activity in stimulated primary murine B cells is dependent on phosphorylation, they leave open the question of whether the binding activity is phosphorylated itself or whether, like NF-kB, its activity might be controlled by phosphorylation of another factor (Ghosh and Baltimore 1990).

\section{Discussion}

We have identified a DNA-binding activity, LR1, that is induced by LPS in cultured primary $B$ cells and that binds specifically to a sequence in the murine switch regions and in the heavy-chain enhancer. Its binding to DNA in vitro is sensitive to dephosphorylation of the nuclear extract. Because LPS stimulates cells through a kinase-mediated pathway, it is likely that LR1 monitors kinase-dependent events in cell regulation and communicates these events to the chromosome.

Two other binding activities that interact with switchregion sequences have been described, but the binding site sequences and patterns of inducibility of both show that they are clearly distinct from LR1. One, called NF$S_{\mu}$ (Wuerffel et al. 1990), is inducible in primary splenocyte culture by LPS in combination with dexamethasone 
and binds a G-rich and highly repeated sequence in $S \mu$. The other, S $\alpha$-BP (Waters et al. 1989), appears to recognize two different sequences in $\mathrm{S} \alpha$ (neither of which resembles the LR1 site). S $\alpha$-BP is not inducible in primary cells, and the dexamethasone required for NF-S $\mu$ induction is not required to induce switching in culture. The LPS inducibility of LR 1 distinguishes it from these other DNA-binding activities, as do the observations that it has sites in each of the $\mathrm{S}$ regions and that its binding is highly sequence specific and phosphorylation dependent.

The inducibility of LR1 activity by LPS is particularly interesting with regard to its site in the heavy-chain enhancer. Both heavy- and light-chain transcription are LPS inducible in primary B cells. Although regulation by NF- $\kappa$ B can account for LPS induction of $\kappa$ transcription (Lenardo et al. 1987), the heavy-chain enhancer has no NF- $k B$ site and an LPS-responsive element has not heretofore been identified in this enhancer region. Future experiments will determine whether LR 1 might play a role in LPS induction of heavy-chain gene expression. The presence of LR1-binding activity in the human B-cell line Raji suggests that LR 1 is conserved between species, and a search of the human heavy-chain enhancer reveals a site that matches the LRl consensus. This site maps just upstream of the E6 region, which functions as a B-cell-specific regulatory element in human cells analogous to the octamer in murine cells (Wang et al. 1991). In the murine heavy-chain enhancer, the LR1 site maps just 18 nucleotides upstream of the octamer sequence. The octamer not only functions as a B-cell-specific regulatory element but also as a promoter for sterile $\mu$ transcription (Su and Kadesch 1990), and the position of the LRl site also suggests that LRI might play a role in regulation of sterile $\mu$ transcripts.

The inducibility, stage specificity, and phosphorylation dependence of LR1 DNA-binding activity, the location of LR1-binding sites in the murine heavy-chain locus, and the kinetics of induction of LR1 activity in LPScultured primary cells are all consistent with a role for LRl in regulation of isotype-switch recombination. When cells are induced to switch in primary culture, LPS serves as a polyclonal mitogen that activates kinase-mediated signaling pathways, while particular lymphokines provide the signal that results in targeted isotype-switch recombination. The presence of LR 1 activity in cell lines derived from pre- $B$ and $B$ cells raises the intriguing possibility that this factor monitors cell activation and functions as an effector that communicates the activation signal to the chromosome.

How might the extracellular signal delivered by LPS activate the recombination apparatus? Alt and his collaborators have suggested that transcription may regulate recombination by modulating the accessibility of DNA to recombination enzymes (Yancopoulos and Alt 1985; Alt et al. 1986; Blackwell et al. 1986). The joining of $\mathrm{V}(\mathrm{D}) \mathrm{J}$ segments to form a functional heavy-chain variable region correlates with production of sterile transcripts from the recombining regions (Yancopoulos and Alt 1985; Schlissel and Baltimore 1989); and in primary murine spleen cells induced to switch in culture as well as in some B-cell lines, the constant region targeted for switch recombination undergoes a low level of transcription, producing sterile transcripts that lack a $\mathrm{V}$ region and are therefore nonfunctional (Stavnezer-Nordgren and Sirlin 1986; Lutzker et al. 1988; Stavnezer et al. 1988; Berton et al. 1989; Esser and Radbruch 1989, Rothman et al. 1990). In a direct test of the effect of transcription on switch recombination, using extrachromosomal substrates transfected into LPS-cultured primary B cells, we have shown recently that a polymerase II promoter can stimulate recombination 10 -fold or more between switch-region sequences $(\mathrm{H}$. Leung and $\mathrm{N}$. Maizels, in prep.). This suggests that LR 1 might function as a transcription factor, and we are currently testing this possibility.

\section{Materials and methods}

Cell culture

For primary cultures, spleen cells from 6- to 8-week BALB/c mice were cultured at $10^{6}$ cells $/ \mathrm{ml}$ at $37^{\circ} \mathrm{C}$ in $5 \% \mathrm{CO}_{2}$ in RPMI 1640 medium supplemented with $10 \%$ fetal bovine serum (GIBCO) and $40 \mu \mathrm{g} / \mathrm{ml}$ of LPS (from Escherichia coli; Sigma no. 2880 ) for 5 days before extract preparation, except where otherwise noted. IL-4 was added at 30-100 U/ml. Transfected I3L6 cell supernatant containing IL4 was generously provided by R. Tepper and P. Leder (1989). Induction of sIgG was measured by FACS or immunofluorescence.

\section{DNA labeling}

Restriction fragments were subcloned by A. Brys from a genomic clone carrying the BALB/c S $\gamma 1$ region, generously provided by W. Dunnick [GenBank file musighanb (Mowatt and Dunnick 1986)]. Synthetic oligonucleotide sequences (with BamHI and/ or BglII ends to facilitate labeling) were from the indicated regions in the following GenBank files: $S \gamma 1$, musighanb 35423573; S $\gamma 3$, musighana 1685-1714; S $\alpha$, musigcd41 1011-1040; E $\mu$, musigcd07 3381-3410. The two strands of each duplex are shown below.

\section{S $\gamma 1:$ 5'd-(GATCCTCCTGGGTCAAGGCTGAATAGACGCAGGGGA) 5 'd-(GATCTCCCCTGCGTCTATTCAGCCTTGACCCAGGAG) \\ G14A: 5'd-(GATCCTCCTGGGTCAAGACTGAATAGACGCAGGGGA) 5'd-(GATCTCCCCTGCGTCTATTCAGTCTTGACCCAGGAG) \\ Sy3: 5 d-(GATCCTGTGGGGACCAGGCTGGACAGCTCTCGGGGA) 5'd-(GATCTCCCCGAGAGCTGTCCAGCCTGGTCCCCACAG) \\ $S \alpha: \quad 5$ 'd-(GATCCGAGCTGGGCTAGGCTGAGCTGAGCTAAACTA) 5'd-(GATCTAGTTTAGCTCAGCTCAGCCTAGCCCAGCTCG) \\ $\mathrm{E} \mu: \quad 5$ 'd-(GATCCCCGAAAGTCCAGGCTGAGCAAAACACCACCA) 5'd-(GATCTGGTGGTGTTTTGCTCAGCCTGGACTTTCGGG)}

Duplexes for binding assays were generated from purified complementary oligonucleotides following the procedure of Hutchison et al. (1986). DNA was labeled to a sp. ac. of $\sim 1 \times 10^{7}$ $\mathrm{cpm} / \mu \mathrm{g}$ with Klenow polymerase and $3000 \mathrm{Ci} / \mathrm{mmole}$ of $\left[\alpha^{-}{ }^{32} \mathrm{P}\right] \mathrm{dATP}$ (Amersham).

\section{Nuclear extract preparation and gel mobility-shift assays}

Nuclear extracts were prepared from primary spleen cells and cell lines by hypotonic lysis followed by Dounce homogenization, as described by Dignam et al. (1983), in buffers supplemented with a protease inhibitor cocktail containing $10-20 \mu \mathrm{g} /$ 
$\mathrm{ml}$ each of aprotinin, leupeptin, pepstatin A (Boehringer Mannheim), and benzamidine (Sigma). Protein concentrations were determined by Bradford microassay (Bio-Rad Laboratories). Gel mobility-shift assays followed the procedures described by Fried and Crothers (1981) and Garner and Revzin (1981). Binding reactions typically contained $10 \mathrm{~mm}$ HEPES $-\mathrm{NaOH}(\mathrm{pH} 7.5) ; 1$ $\mathrm{mm} \mathrm{DTT}, 200 \mathrm{~mm} \mathrm{KCl}, 2 \%$ (wt/vol) polyvinylalcohol, 5\% (vol/ vol) glycerol, $0.2 \mu \mathrm{g}$ of poly[d(IC)] (Boehringer Mannheim), $1000-5000 \mathrm{cpm}$ of probe DNA, and $5 \mu \mathrm{g}$ of protein in a final volume of $10 \mu \mathrm{l}$. Binding reactions were incubated at room temperature for $20 \mathrm{~min}$ and loaded into $1.5 \times 6-\mathrm{mm}$ wells of a $5 \%$ polyacrylamide gel $(29: 1$ acrylamide/bis-acrylamide) in $1 \times$ TBE buffer ( $90 \mathrm{~mm}$ Tris-borate, $2.5 \mathrm{~mm}$ EDTA at $\mathrm{pH} 8.3$ ), which had been prerun at $6-10 \mathrm{~V} / \mathrm{cm}$ for $0.5 \mathrm{hr}$. Gels were run at 2 $\mathrm{V} / \mathrm{cm}$ while loading and for 6-10 min thereafter, whereupon voltage was increased to $6-10 \mathrm{~V} / \mathrm{cm}$ for $2-3 \mathrm{hr}$. Gels were dried and autoradiographed at $-70^{\circ} \mathrm{C}$ with an intensifying screen. Activity of total protein in extracts lacking LR1 activity was verified by mobility shifts that assayed binding to the octanucleotide sequence from the U2 promoter, which binds the Oct- 1 factor ubiquitous in mammalian cells (Ares et al. 1987).

\section{Methylation interference}

For methylation interference experiments (Siebenlist and Gilbert 1980), $\sim 10^{6} \mathrm{cpm}$ of $3^{\prime}$ end-labeled BamHI-PstI or DdeIPst fragment was partially methylated with dimethylsulfate; following incubation with nuclear extract, the bound and free DNA molecules were resolved by native gel electrophoresis, eluted, treated with $10 \mathrm{~mm}$ sodium phosphate $(\mathrm{pH} 7.0), 1 \mathrm{~mm}$ EDTA at $90^{\circ} \mathrm{C}$ for $15 \mathrm{~min}$, followed by $0.15 \mathrm{M} \mathrm{NaOH}, 0.1 \mathrm{~mm}$ EDTA, at $90^{\circ} \mathrm{C}$ for $15 \mathrm{~min}$. Reaction products were analyzed on an $8 \%$ polyacrylamide $-8 \mathrm{M}$ urea gel.

\section{Phosphatase treatment of nuclear extracts}

Acid phosphatase from potato (grade I, Boehringer Mannheim) was spun out of ammonium sulfate suspension and resuspended in $10 \mathrm{~mm}$ MES ( $\mathrm{pH} 6)$. Nuclear extracts ( $2-5 \mu \mathrm{g}$ of protein) were incubated with 60 milliunits of acid phosphatase in $10 \mathrm{~mm} 2[\mathrm{~N}$ morpholino]ethane sulfonic acid (MES) (pH 6) in a final volume of $6 \mu \mathrm{l}$, at $25^{\circ} \mathrm{C}$ for $10 \mathrm{~min}$. A $3-\mu \mathrm{l}$ aliquot of the phosphatasetreated sample was then used in each $10-\mu$ l binding assay.

\section{Acknowledgments}

We thank W. Dunnick for the clone containing the BALB/c genomic S $\gamma 1$ region; $R$. Tepper and P. Leder for IL-4-containing I3L6 supernatant; A. Brys for subclones of the S $\gamma 1$ switch region; R. Ach, B. Gavin, and Z. Pitluk for providing the HeLa, S49, and A92L nuclear extracts, respectively; and G. Howe for providing Raji cell extracts used in initial experiments. We thank our neighbors in $\mathrm{C}$-wing basement for helpful discussions, especially H. Leung, K. Derbyshire, and Z. Pitluk. M.W. was supported by National Institute of Health, National Research Service Award Institutional grant 5T32 GM07223, and this work was supported by U.S. Public Health Services grant GM39799.

The publication costs of this article were defrayed in part by payment of page charges. This article must therefore be hereby marked "advertisement" in accordance with 18 USC section 1734 solely to indicate this fact.

\section{References}

Alt, F.W., T.K. Blackwell, R.A. DePinho, M.G. Reth, and G.D. Yancopoulos. 1986. Regulation of genome rearrangement events during lymphocyte differentiation. Immunol. Rev. 78: 5-29.

Ares, M., J.-S. Chung, L. Giglio, and A.M. Weiner. 1987. Distinct factors with Sp1 and NF-A specificities bind to adjacent functional elements of the human U2 snRNA gene enhancer. Genes \& Dev. 1: 808-817.

Bergstedt-Lindqvist, S., P. Sideras, H.R. MacDonald, and E. Severinson. 1984. Regulation of Ig class secretion by soluble products of certain $T$ cell lines. Immunol. Rev. 78: 25-50.

Berton, M.T., J.W. Uhr, and E.S. Vitetta. 1989. Synthesis of germ-line $\gamma 1$ immunoglobulin heavy-chain transcripts in resting B cells: Induction by interleukin 4 and inhibition by interferon $\gamma$. Proc. Nat1. Acad. Sci. 86: 2829-2833.

Bijsterboch, M.K., C.J. Meade, G.A. Turner, and G.G.B. Klaus. 1985. B lymphocyte receptors and phosphoinositide degradation. Cell 41: 999-1006.

Bijsterboch, M.K., K.P. Rigley, and G.G.B. Klaus. 1986. Crosslinking of surface immunoglobulin on B lymphocytes induces both intracellular $\mathrm{Ca}^{++}$release and $\mathrm{Ca}^{++}$influx: Analysis with indo-1. Biochem. Biophys. Res. Comm. 137: 500-506.

Blackwell, T.K. and F.W. Alt. 1989. Mechanism and developmental program of immunoglobulin gene rearrangement in mammals. Annu. Rev. Genet. 23: 605-636.

Blackwell, K., M. Moore, G.D. Yancopoulos, H. Suh, S. Lutzker, E. Selsing, and F.W. Alt. 1986. Recombination between immunoglobulin variable region gene segments is enhanced by transcription. Nature 324: 585-589.

Coffman, R.L. and J. Carty. 1986. A T cell activity that enhances polyclonal IgE production and its inhibition by interferongamma. J. Immunol. 138: 3688-3694.

Coffman, R.L., J. Ohara, M.W. Bond, J. Carty, A. Zlotnik, and W.E Paul. 1986. B cell stimulatory factor-1 enhances the IgE response of lipopolysaccharide-activated B cells. I. Immunol. 136: 4538-4541.

Coffman, R.L., D.A. Lebman, and B. Shrader. 1989. Transforming growth factor beta specifically enhances IgA production by lipopolysaccharide-stimulated murine B lymphocytes. I. Exp. Med. 170: 1039-1044.

Davis, M.M., S.K. Kim, and L.E. Hood. 1980. DNA sequences mediating class switching in alpha-immunoglobulins. Science 209: 1360-1365.

Dignam, J.D., R.M. Lebovitz, and R.G. Roeder. 1983. Accurate transcription initiation by RNA polymerase II in a soluble extract from isolated mammalian nuclei. Nucleic Acids Res. 11: 1475-1489.

Dunnick, W., T.H. Rabbitts, and C. Milstein. 1980. An immunoglobulin deletion mutant with implications for the heavychain switch and RNA splicing. Nature 286: 669-675.

Esser, C. and A. Radbruch. 1989. Rapid induction of transcription of unrearranged Sgammal switch regions in activated murine B cells by interleukin 4. EMBO I. 8: 483-488.

- 1990. Immunoglobulin class switching: Molecular and cellular analysis. Annu. Rev. Immunol. 8: 717-735.

Finkelman, F.D., I.M. Katona, T.R. Mosmann, and R.L. Coffman. 1988. IFN-gamma regulates the isotypes of Ig secreted during in vivo humoral immune responses. I. Immunol. 140: 1022-1027. 
Fried, M. and D.M. Crothers. 1981. Equilibria and kinetics of lac repressor-operator interactions by polyacrylamide gel electrophoresis. Nucleic Acids Res. 9: 6506-6525.

Garner, M.M. and A. Revzin. 1981. A gel electrophoresis method for quantifying the binding of proteins to specific DNA regions: Application to components of the Escherichia coli lactose operon regulatory system. Nucleic Acids Res. 9: 3047-3060.

Ghosh, S. and D. Baltimore. 1990. Activation in vitro of NFkappaB by phosphorylation of its inhibitor. Nature 344: 678-682.

Guy, G.R., J. Gordon, R.H. Michell, and G. Brown. 1985. Synergism between diacylglycerols and calcium ionophore in the induction of human B cell proliferation mimics the inositiol lipid polyphosphate breakdown signals induced by crosslinking surface immunoglobulin. Biochem. Biophys. Res. Comm. 131: 484-491.

Hoeffler, W.K., F. Liu, E.A. Allegretto, M. Karin, and M.R. Green. 1988. A family of immunologically related transcription factors that includes multiple forms of ATF and AP-1. Genes \& Dev. 2: 1216-1226.

Howard, M., and W.E. Paul. 1983. Regulation of B-cell growth and differentiation by soluble factors. Annu. Rev. Immunol 1: 307-334.

Hutchison, C.A., S.K. Nordeen, K., Vogt, and M.H. Edgell. 1986. A complete library of point substitution mutations in the glucocorticoid response element of the mouse mammary tumor virus. Proc. Natl. Acad. Sci. 83: 710-714.

Isakson, P., E. Pure, E.S. Vitetta, and P.H. Krammer. 1982. T cell-derived B cell differentiation factor(s): Effect on the isotype switch of murine B cells. J. Exp. Med. 155: 734-748.

Jackson, S.P., J.J. MacDonald, S. Lees-Miller, and R. Tjian. 1990. GC box binding induces phosphorylation of $\mathrm{Sp} 1$ by a DNAdependent protein kinase. Cell 63: 155-165.

Kataoka, T., T. Kawakami, N. Takahashi, and T. Honjo. 1980. Rearrangement of immunoglobulin gammal-chain gene and mechanism for heavy-chain class switch. Proc. Natl. Acad. Sci. 77: 919-923.

Kataoka, T., T. Miyata, and T. Honjo. 1981. Repetitive sequences in class-switch recombination regions of immunoglobulin heavy chain genes. Cell 23: 357-368.

Keath, E.J., A. Kelekar, and M.D. Cole. 1984. Transcriptional activation of the translocated c-myc oncogene in mouse plasmacytomas: Similar RNA levels in tumor and proliferating normal cells. Cell 37: 521-528.

Lenardo, M.J., J.W. Pierce, and D. Baltimore. 1987. Protein-binding sites in $\mathrm{Ig}$ gene enhancers determine transcriptional activity and inducibility. Science 236: 1573-1577.

Lutzker, S., P. Rothman, R. Pollock, R. Coffman, and F.W. Alt. 1988. Mitogen- and IL-4-regulated expression of germ-line Ig gamma2b transcripts: Evidence for directed heavy chain class switching. Cell 53: 177-184.

Mohr, I.J., B. Stillman, and Y. Gluzman. 1987. Regulation of SV40 DNA replication by phosphorylation of $\mathrm{T}$ antigen. EMBO J. 6: 153-160.

Mowatt, M.R. and W.A. Dunnick. 1986. DNA sequence of the murine gammal switch segment reveals novel structural elements. I. Immunol. 136: 2674-2683.

Nikaido, T., S. Nakai, and T. Honjo. 1981. Switch region of immunoglobulin Cmu gene is composed of simple tandem repetitive sequences. Nature 292: 845-848.

Nikaido, T., Y. Yamawaki-Kataoka, and T. Honjo. 1982. Nucleotide sequences of switch regions of immunoglobulin Cepsilon and Cgamma genes and their comparison. J. Biol. Chem. 257: 7322-7329.

Noma, Y., P. Sideras, T. Naito, S. Bergstedt-Lindqvist, C.
Azuma, E. Severinson, T. Tanabe, T. Kinashi, F. Matsuda, Y. Yaoita, and T. Honjo. 1986. Cloning of cDNA encoding the murine IgG1 induction factor by a novel strategy using SP6 promoter. Nature 319: 640-646.

Paul, W. and J. Ohara. 1987. B-cell stimulatory factor-1/interleukin 4. Annu. Rev. Immunol. 5: 429-459.

Prywes, R., A. Dutta, J.A. Cromlish, and R.G. Roeder. 1988. Phosphorylation of serum response factor, a factor that binds to the serum response element of the c-fos enhancer. Proc. Natl. Acad. Sci. 85: 7206-7210.

Radbruch, A. and F. Sablitzky. 1983. Deletion of Cmu genes in mouse B lymphocytes upon stimulation with LPS. EMBO J. 2: 1929-1935.

Raychaudhuri, P., S.K. Bagchi, and J. R. Nevins. 1989. DNAbinding activity of the adenovirus-induced E4F transcription factor is regulated by phosphorylation. Genes \& Dev. 3: $620-627$.

Rothman, P., Y.-Y. Chen, S. Lutzker, S.C. Li, V. Stewart, R. Coffman, and F.W. Alt. 1990. Structure and expression of germ line immunoglobulin heavy-chain epsilon transcripts: Interleukin-4 plus lipopolysaccharide-directed switching to Cepsilon. Mol. Cell. Biol. 10: 1672-1679.

Sakano, H., R. Maki, Y. Kurosawa, W. Roeder, and S. Tonegawa. 1980. Two types of somatic recombination are necessary for the generation of complete immunoglobulin heavy chain genes. Nature 286: 676-683.

Schlissel, M.S. and D. Baltimore. 1989. Activation of immunoglobulin kappa gene rearrangement correlates with induction of germline kappa gene transcription. Cell 58: 10011007.

Sen, D. and W. Gilbert. 1988. Formation of parallel fourstranded complexes by guanine- rich motifs in DNA and its implications for meiosis. Nature 334: 364-366.

Siebenlist, U. and W. Gilbert. 1980. Contacts between E. coli RNA polymerase and an early promoter of phage T7. Proc. Natl. Acad. Sci. 77: 122-126.

Snapper, C.M. and W.E. Paul. 1987. Interferon-gamma and B cell stimulatory factor- 1 reciprocally regulate Ig isotype production. Science 236: 944-947.

Snapper, C.M., C. Peschel, and W.E. Paul. 1988. Interferongamma stimulates IgG2a secretion by murine B cells stimulated with bacterial lipopolysaccharide. I. Immunol. 140: 2121-2126.

Stavnezer-Nordgren, J. and S. Sirlin. 1986. Specificity of immunoglobulin heavy chain switch correlates with activity of germline heavy chain genes prior to switching. EMBO $\%$ 5: 95-102.

Stavnezer, J., G. Radcliffe, Y.-C. Lin, J. Nietupski, L. Berggren, R. Sitia, and E. Severinson. 1988. Immunoglobulin heavy chain switching may be directed by prior induction of transcripts from constant-region genes. Proc. Natl. Acad. Sci. 85: 7704-7708.

Su, L. -K. and T. Kadesch. 1990. The immunoglobulin heavychain enhancer functions as the promoter for Imu sterile transcription. Mol. Cell. Biol. 10: 2619-2624.

Szurek, P., J. Petrini, and W. Dunnick. 1985. Complete nucleotide sequence of the murine gamma3 switch region and analysis of switch recombination sites in two gamma3-expressing hybridomas. I. Immunol. 135: 620-626.

Tanaka, M. and W. Herr. 1990. Differential transcriptional activation by Oct-1 and Oct-2: Interdependent activation domains induce Oct-2 phosphorylation. Cell 60: 375-386.

Tepper, R. and P. Leder. 1989. Murine interleukin-4 displays potent anti-tumor activity in vivo. Cell 57: 503-512.

Vitetta, E., J. Ohara, F. Meyers, J. Layton, P.H. Krammer, and W.E. Paul. 1985. Serological, biochemical and functional 
identification of B cell stimulatory factor- 1 and B cell differentiation factor for IgGl. J. Exp. Med. 162: 1726-1735.

Wang, J., M. Oketani, and T. Watanabe. 1991. Positive and negative regulation of immunoglobulin gene expression by a novel B-cell-specific enhancer element. Mol. Cell. Biol. 11: $75-83$.

Waters, S.H., K.U. Saikh, and J. Stavnezer. 1989. A B-cell-specific nuclear protein that binds to DNA sites $5^{\prime}$ to immunoglobulin Salpha tandem repeats is regulated during differentiation. Mol. Cell. Biol. 9: 5594-5601.

Wuerffel, R.A., A.T. Nathan, and A.L. Kenter. 1990. Detection of an immunoglobulin switch region-specific DNA-binding protein in mitogen-stimulated mouse splenic B cells. Mol. Cell. Biol. 10: 1714-1718.

Yancopoulos, G.D. and F.W. Alt. 1985. Developmentally controlled and tissue-specific expression of unrearranged $\mathrm{VH}$ gene segments. Cell 40: 271-281. 


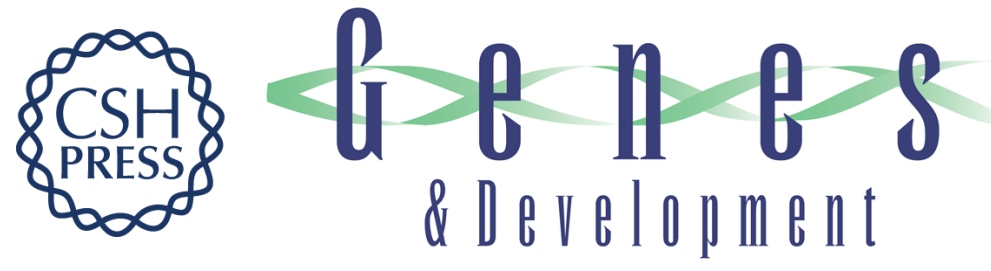

\section{LR1, a lipopolysaccharide-responsive factor with binding sites in the immunoglobulin switch regions and heavy-chain enhancer.}

M Williams and N Maizels

Genes Dev. 1991, 5:

Access the most recent version at doi:10.1101/gad.5.12a.2353

References This article cites 58 articles, 26 of which can be accessed free at:

http://genesdev.cshlp.org/content/5/12a/2353.full.html\#ref-list-1

License

Email Alerting

Service

Receive free email alerts when new articles cite this article - sign up in the box at the top right corner of the article or click here.

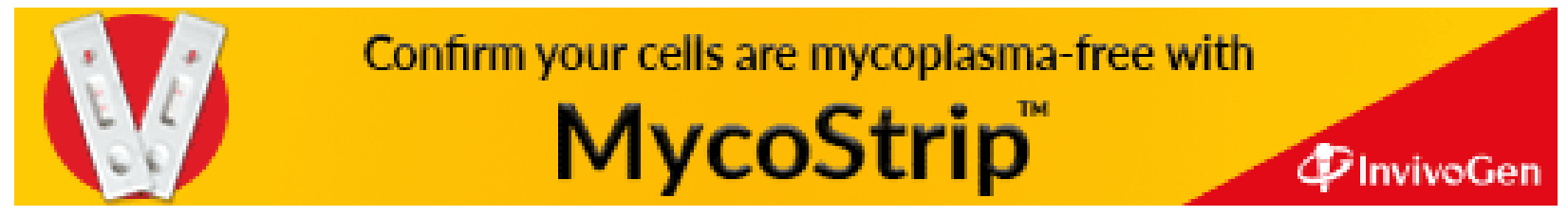

